\title{
Triple-band Slot Antenna Array for Energy Harvesting for Wireless Sensor Networks
}

\author{
Wen-Shan Chen, Chien-Min Cheng, ${ }^{*}$ Bo-Yu Liao, Yao-Lin Chang, and Hsin-Yu Wang \\ Department of Electronic Engineering, Southern Taiwan University of Science and Technology \\ No. 1, Nan-Tai Street, Yungkang Dist., Tainan City 710, Taiwan R.O.C.
}

(Received November 15, 2017; accepted December 19, 2017)

Keywords: slot antenna, antenna array, energy harvesting, triple-band, wireless sensor network

An energy harvesting antenna array for wireless sensor applications is presented in this paper. The microstrip line feeding network excites four slots to achieve wireless local-areanetwork (WLAN) 2.4/5.2/5.8 (2.4-2.484/5.15-5.325/5.725-5.825 GHz) bands. The design is printed on a flame retardant 4 (FR4) substrate with thickness of $1.6 \mathrm{~mm}$, permittivity of 4.4 , and loss tangent of 0.0245 . The overall size of the antenna array is only $60 \times 60 \times 1.6 \mathrm{~mm}^{3}$ and, with dual-ports, consists of two antenna arrays; port 1 is designed for a WLAN $2.4 \mathrm{GHz}$ band and port 2 is designed for a WLAN 5.2/5.8 GHz band. The feeding network (electric length $\left.=\lambda_{g} / 4\right)$ was used to connect the array network and antenna, and for the purpose of in phase excitation, we used microstrip lines (electric length $=\lambda_{g} / 2$ ) to adjust the phase difference of these two antenna elements to $180^{\circ}$. Finally, $8 \mathrm{~mm}$ above the antenna array, we placed a metal reflector the same size as the antenna to adjust the radiation patterns to the $-y$ direction and to enhance the radiation directivity and gains.

\section{Introduction}

With the continuous progress of the Internet of Things (IoT), sustainable electric power has played an important role in the development of all kinds of electronic products. Additionally, by energy harvesting and wireless power transmission techniques, environmental energies (solar energy, heat, electromagnetic energy, vibration energy, etc.) may be harvested and transformed to electrical energy for the applications of the modern products of the IoT. The dipole design technique has been used to develop antennas applied to energy receivers or transducers. ${ }^{(1,2)}$ For converting and harvesting the RF energy, a rectenna array with high gains, linear polarization, and miniature structure was designed, which can be matched to rectifier circuits. ${ }^{(3-6)}$ A dualband Yagi antenna was designed for the global system for mobile communications (GSM-1800) and for universal mobile telecommunications system (UMTS-2100) bands. The antenna gains for GSM-1800 and UMTS-2100 bands are up to 10.9 and $13.3 \mathrm{dBi}$, respectively. Hence, through the circuits, this antenna can be used in energy harvesting for electric power of 300-400 $\mathrm{mW} .^{(7)}$ An antenna with a simple structure, a central frequency of $2.45 \mathrm{GHz}$, a gain of $8 \mathrm{dBi}$,

*Corresponding author: e-mail: ccmin523@gmail.com

http://dx.doi.org/10.18494/SAM.2018.1827 
and an efficiency of 50\% was presented and applied to energy conversion. ${ }^{(8)}$ An antenna was developed for energy harvesting systems and for cooling performance concerns, for which the authors used a vertical metal plate to diminish the inference of back-lobe effects. ${ }^{(9,10)}$ Using the microstrip structure, the authors developed an antenna with high gains that can be applied to WiFi and to the Portuguese digital terrestrial television (DTT) signal of $0.754 \mathrm{GHz} .{ }^{(11,12)}$ The combination of patch and slot techniques was achieved, a dual-fed slotted circular polarization antenna was designed and with the reflector, high antenna gains were easily obtained. ${ }^{(13,14)}$ The signal transmitted from a cell tower can be received easily through the energy harvesting system; its operating band was $0.877-0.998 \mathrm{GHz}$ and the optimum gain was up to $9.1 \mathrm{dBi}^{(15)}$ As mentioned, it can be seen that, by using an antenna array and rectified circuits, AC electromagnetic energy can be received and transformed to DC energy for application to low power electronic products. In this paper, using the slots and two pairs of antenna arrays, we excite triple bands of wireless local-area-network (WLAN) 2.4-2.484, 5.15-5.35, and 5.725-5.825 GHz. Finally, for sensing and converting electromagnetic energy effectively, we also used a metal reflector to enhance the gains, modify the radiation patterns, and improve the directivity for future energy harvesting applications.

\section{Antenna Design}

The proposed $60 \times 60 \times 1.6 \mathrm{~mm}^{3}$ slot antenna operating at WLAN 2.4-2.484, 5.15-5.325, and $5.725-5.825 \mathrm{GHz}$ was fabricated on a flame retardant 4 (FR4) substrate, which was $1.6 \mathrm{~mm}$ thick and has a permittivity of 4.4 and a loss tangent of 0.0245 . As indicated by the geometry shown in Fig. 1(a), the $50 \Omega$ microstrip line was used to feed into ports 1 and 2. Additionally,

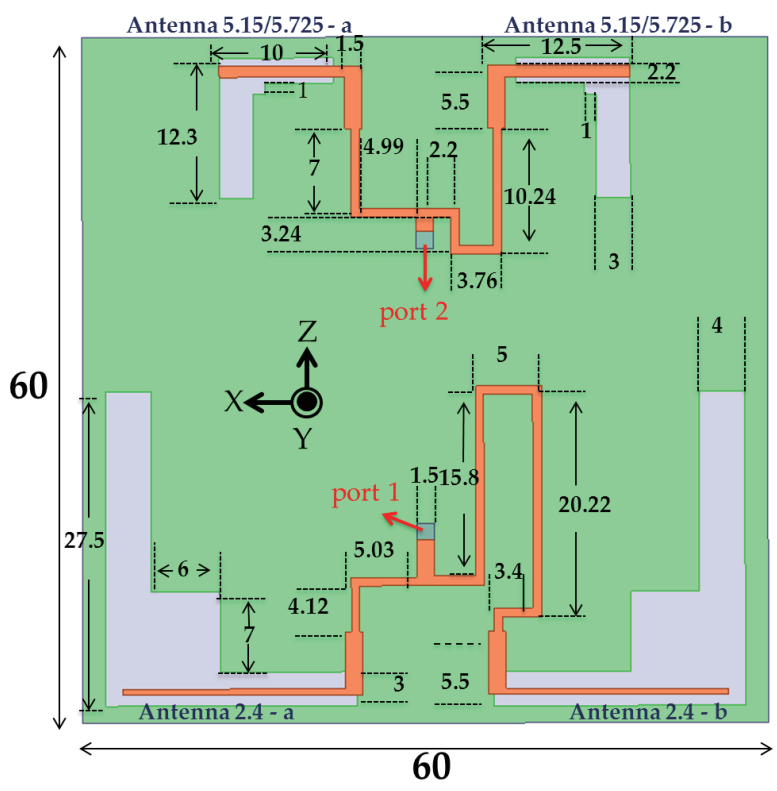

(a)

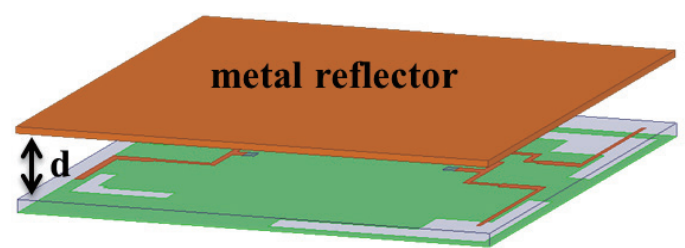

(b)

Fig. 1. (Color online) Geometry of the designed antenna array. (a) Top and (b) 3-D views. 
two pairs of antennas (leveled Antenna 5.15/5.825-a, Antenna 5.15/5.825-b, Antenna 2.4-a, and Antenna 2.4-b) were designed, and the total length of the slot was $\lambda_{g} / 2$ (the electric lengths of 2.4 and $5.15 \mathrm{GHz}$ are 60 and $29 \mathrm{~mm}$, respectively). For antenna gains, radiation efficiency, and directivity improvement, a metal reflector $\left(60 \times 60 \times 0.8 \mathrm{~mm}^{3}\right)$ of the same size as the substrate was placed upon the proposed antenna at a distance of $d$ from the array, as Fig. 1(b) shows. The design is composed of two pairs of arrays of antennas; in addition, Antenna 2.4a and Antenna 2.4-b are operated at the WLAN $2.4 \mathrm{GHz}$ band, while Antenna 5.15/5.825-a and Antenna 5.15/5.825-b are operated at the WLAN 5.2/5.8 GHz bands. In this array, the same impedance was designed for these two pairs of antennas, but because of the different operating bands ( 2.4 and 5.2/5.8 GHz), their electric lengths were unequal. Figure 2 shows the microstrip line feeding network; sections bc and fh are $100 \Omega$ micristrip lines with electric lengths of $\lambda_{g} / 4$ and widths of $0.7 \mathrm{~mm}$; they connect to upper slots. Because the phase differences between these two pairs of antennas (Antenna 5.15/5.825-a and Antenna 5.15/5.825-b, Antenna 2.4-a and Antenna 2.4-b) are all equal to $180^{\circ}$, we inserted $\lambda_{g(2.4)} / 2$ (theoretical value) into section bd and $\lambda_{g(5.15 / 5.825)} / 2$ (theoretical value) into section fg to adjust their phase differences, as Eqs. (1)(4) described. Hence, for these antenna pairs, in-phase excitation and gains improvement can be obtained easily and, at this point, the impedances of point $b$ and point $f$ are equal to $50 \Omega$ because the two $100 \Omega$ (bc in parallel with bd; fh in parallel with fg) are in parallel.
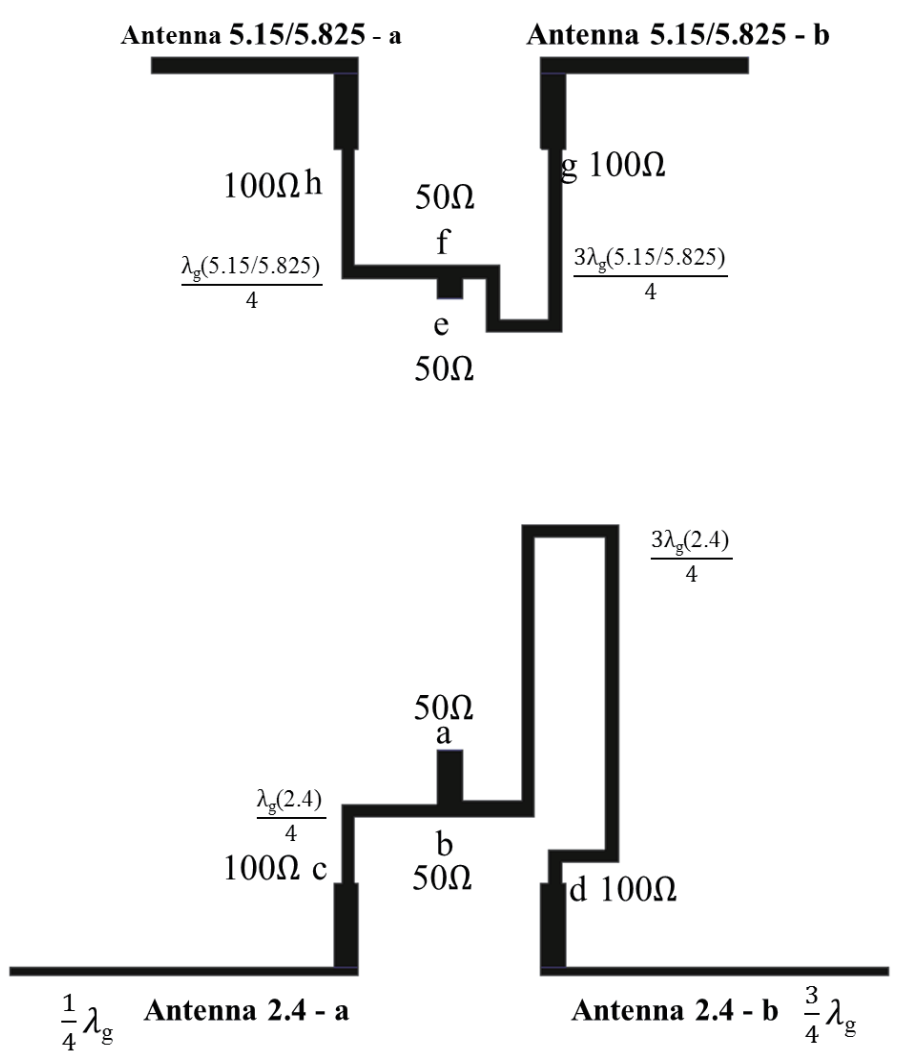

Fig. 2. Microstrip line feeding network and impedance of nodes. 


$$
\begin{aligned}
\overline{\mathrm{fh}} & =\frac{1}{4} \lambda_{g(5.15 / 5.825)} \\
\overline{\mathrm{fg}} & =\frac{3}{4} \lambda_{g(5.15 / 5.825)} \\
\overline{\mathrm{bc}} & =\frac{1}{4} \lambda_{g(2.4)} \\
\overline{\mathrm{bd}} & =\frac{3}{4} \lambda_{g(2.4)}
\end{aligned}
$$

\section{Results and Discussion}

To investigate the inferences corresponding to different distances ( $d$ values) of the metal reflector, Figs. 3-5 show the simulated return loss $\left(\mathrm{S}_{11}\right.$ and $\left.\mathrm{S}_{22}\right)$ and antenna gains (at $-y$ direction) at low operating frequency $(2.4-2.484 \mathrm{GHz})$ and high operating frequency $(5.15-5.325$ and $5.725-5.825 \mathrm{GHz}$ ). Figure 3 shows that, as the distance increases, the bandwidth of 2.4-2.484 $\mathrm{GHz}$ bands increases from $120 \mathrm{MHz}(d=6 \mathrm{~mm})$ to greater than $620 \mathrm{MHz}(d=30 \mathrm{~mm})$. But the overall dimensions are too large for practical applications when $d=30 \mathrm{~mm}$. The simulated optimum antenna gain $(4.5 \mathrm{dBi})$ occurs at $d=8 \mathrm{~mm}$ for the $2.4-2.484 \mathrm{GHz}$ bands. Figures 4 and 5 show the simulated $\mathrm{S}_{22}$ values and antenna gains (in the $-y$ direction) of 5.15-5.325 and $5.725-5.825 \mathrm{GHz}$ bands. It can be seen that the bandwidth reveals the same tendency as at low frequency. The simulated optimum antenna gains are $6 \mathrm{dBi}(d=6 \mathrm{~mm})$ and $5.7 \mathrm{dBi}(d=8 \mathrm{~mm})$ for the 5.15-5.325 GHz bands and 5.725-5.825 GHz bands, respectively. By considering the simulated antenna characteristics and the final overall dimensions, in this study we chose $8 \mathrm{~mm}$ as the optimum distance between the metal reflector and the antenna array.

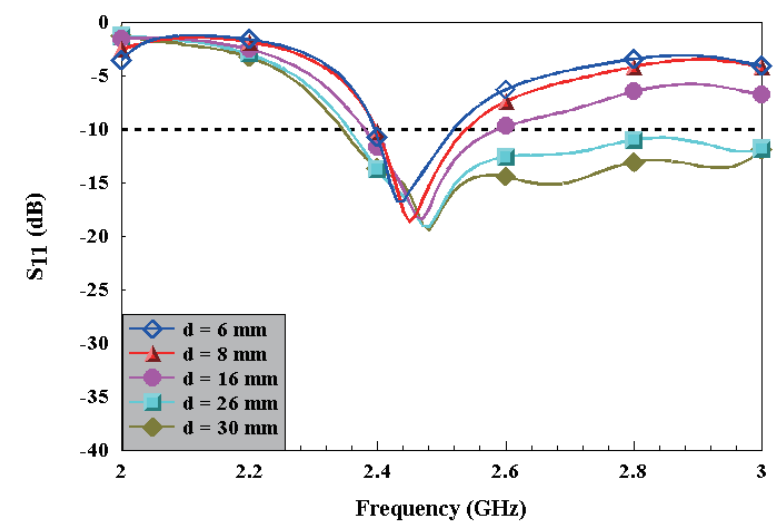

(a)

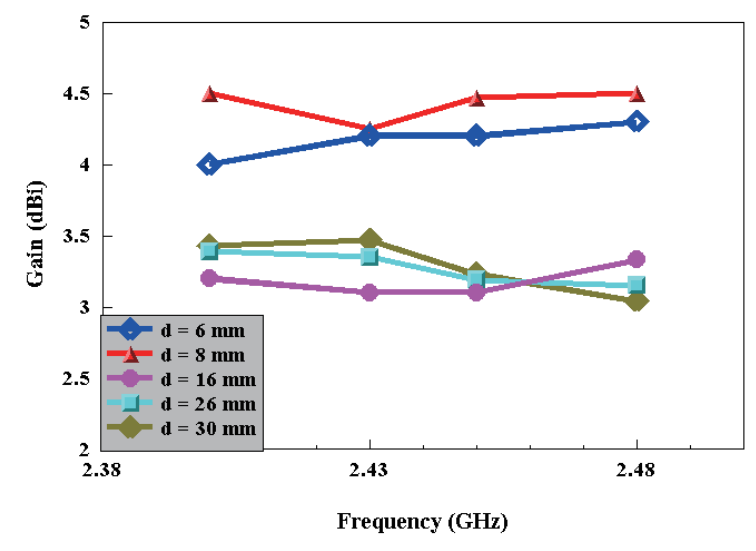

(b)

Fig. 3. (Color online) (a) Simulated $S_{11}$ and (b) antenna gains (in the $-y$ direction) for different $d$ values (2.4-2.484 $\mathrm{GHz}$. 


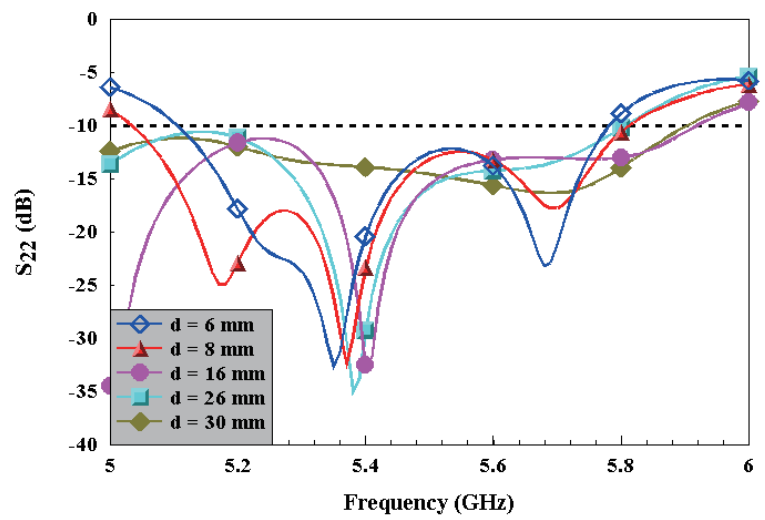

Fig. 4. (Color online) Simulated $S_{22}$ parameters (in the $-y$ direction) for different $d$ values $(5.15-5.825 \mathrm{GHz}$ ).

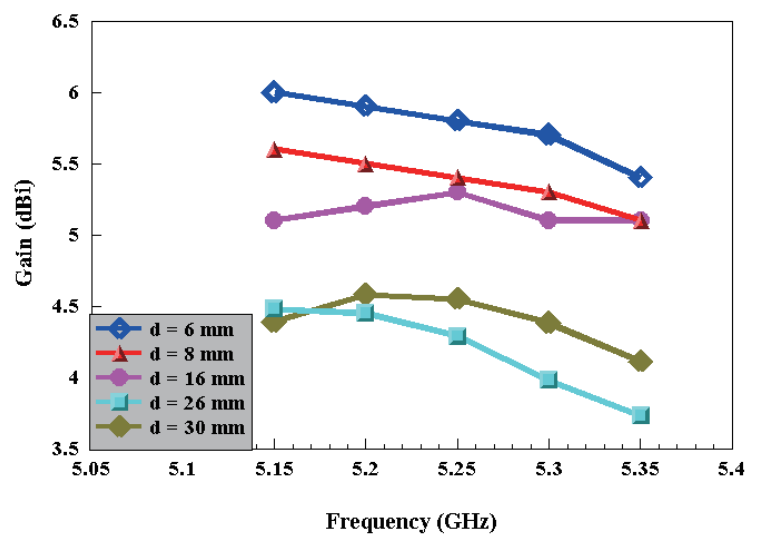

(a)

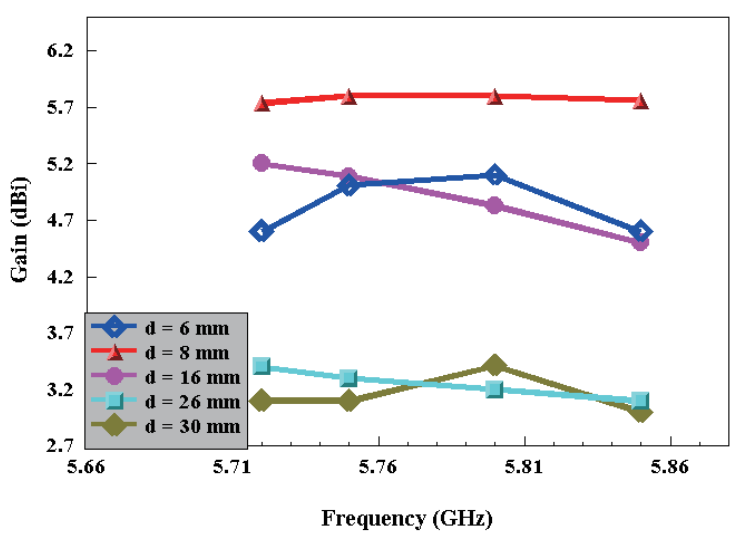

(b)

Fig. 5. (Color online) Simulated antenna gains (in the $-y$ direction) for different $d$ values.

When the metal reflector was placed in the $+y$ direction at a distance of $8 \mathrm{~mm}$, Fig. 6 shows the simulated and measured $\mathrm{S}$ parameters $\left(\mathrm{S}_{11}, \mathrm{~S}_{12}\right.$, and $\left.\mathrm{S}_{22}\right)$ of the proposed antenna in the $-y$ direction. It can be observed that all the measured $\mathrm{S}$ parameters are in good agreement with the simulated ones for the $2.4-2.484 \mathrm{GHz}$ bands. All the $\mathrm{S}_{11}$ values are below $-10 \mathrm{~dB}$, and the measured isolation $\left(\mathrm{S}_{12}\right)$ is lower than $-24 \mathrm{~dB}$; this means that the mutual effect of these two antennas is only $0.4 \%$. On the other hand, for the $5.15-5.825 \mathrm{GHz}$ bands, all the $\mathrm{S}_{11}$ values are below $-10 \mathrm{~dB}$ and some disagreement in the $S$ parameters is observed due to fabrication errors. Finally, the measured $\mathrm{S}_{12}$ is lower than $-25 \mathrm{~dB}$; this means that the mutual effect of these two antennas is only $0.32 \%$, which is low enough for modern sensor or energy harvesting applications.

Figure 7 shows the measured 2-D radiation patterns of the designed antennas with a metal reflector at $8 \mathrm{~mm}$ distance for $2.45,5.15$, and $5.82 \mathrm{GHz}$, respectively. Comparing all the $X-Y$ and $Y-Z$ planes, it can be observed that, owing to the metal reflector, all the radiation patterns of these bands become more focused in the $-y$ direction, especially the $2.45 \mathrm{GHz}$ radiation. This means that the proposed antenna has the advantage of good directivity in the $-y$ direction. For 


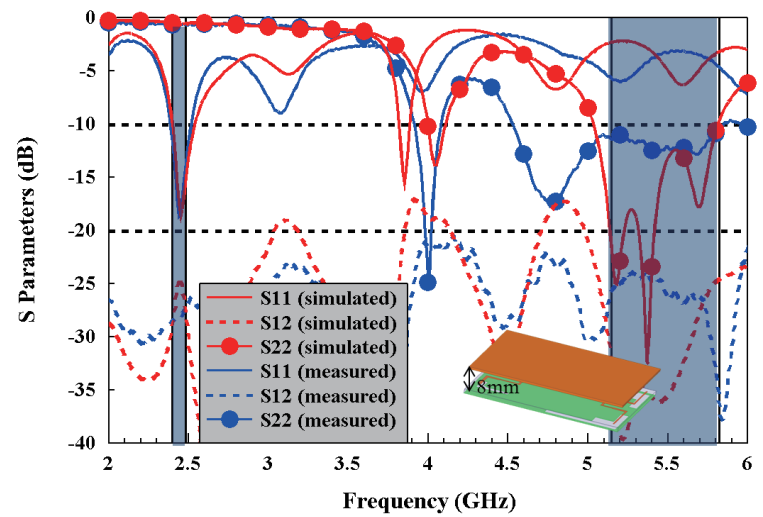

Fig. 6. (Color online) Measured and simulated S Parameters (in the $-y$ direction) of the proposed antenna $(d=8$ $\mathrm{mm}$ ).

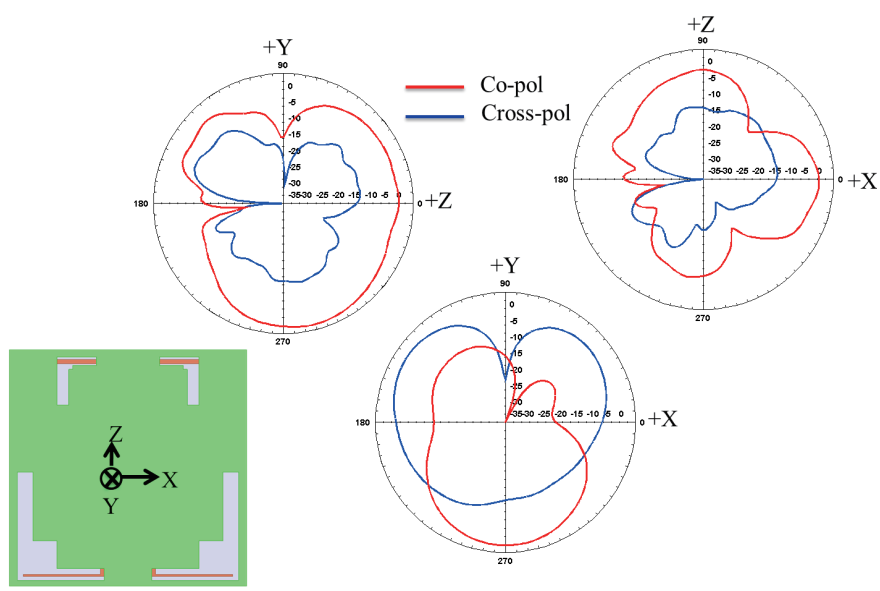

(a)

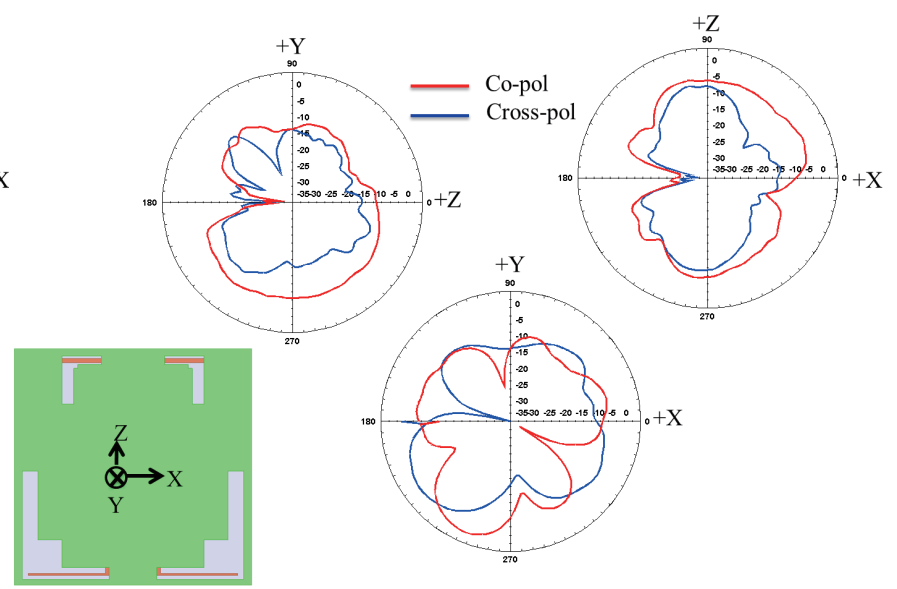

(b)

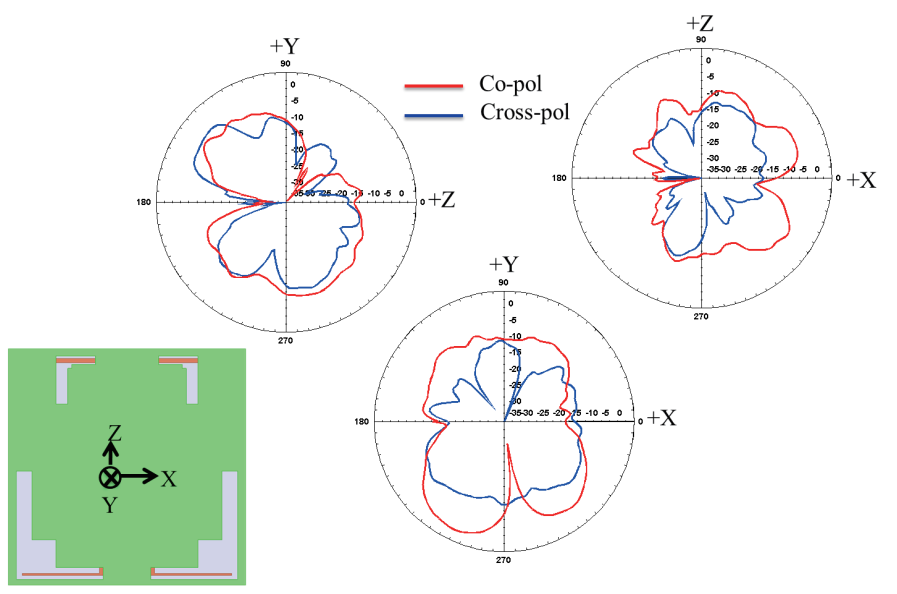

(c)

Fig. 7. (Color online) Measured 2-D radiation patterns ( $d=8 \mathrm{~mm}$ ). (a) 2.45, (b) 5.25, and (c) $5.75 \mathrm{GHz}$. 
high frequencies, the wavelength of the $5 \mathrm{GHz}$ band is only about $14 \mathrm{~mm}$, but the dimensions of the proposed antenna are $60 \times 60 \times 1.6 \mathrm{~mm}^{3}$, which is bigger than the wavelength. As the microstrips couple with ground plane and generate high frequency bands, more null points and shifts of radiation patterns are observed for 5.25 and $5.75 \mathrm{GHz}$.

The measured antenna gains and radiation efficiencies (in the $-y$ direction) of the proposed design with metal reflector at $8 \mathrm{~mm}$ distance (in the $+y$ direction) are shown in Fig. 8 and collated in Table 1. For the 2.4-2.484 GHz bands, the antenna gains varied between 3.5 and 4 $\mathrm{dBi}$, and the radiation efficiencies varied from 60 to $69 \%$. For the $5.15-5.35 \mathrm{GHz}$ bands, the antenna gains varied between 5.1 and $6 \mathrm{dBi}$, and the radiation efficiencies varied from 52 to $59 \%$. Finally, for the $5.725-5.825 \mathrm{GHz}$ bands, the antenna gains varied between 5.2 and 5.8

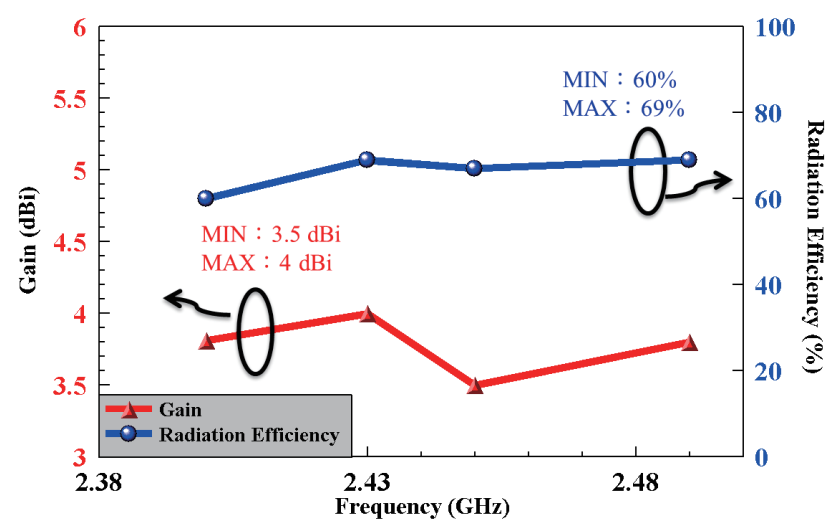

(a)

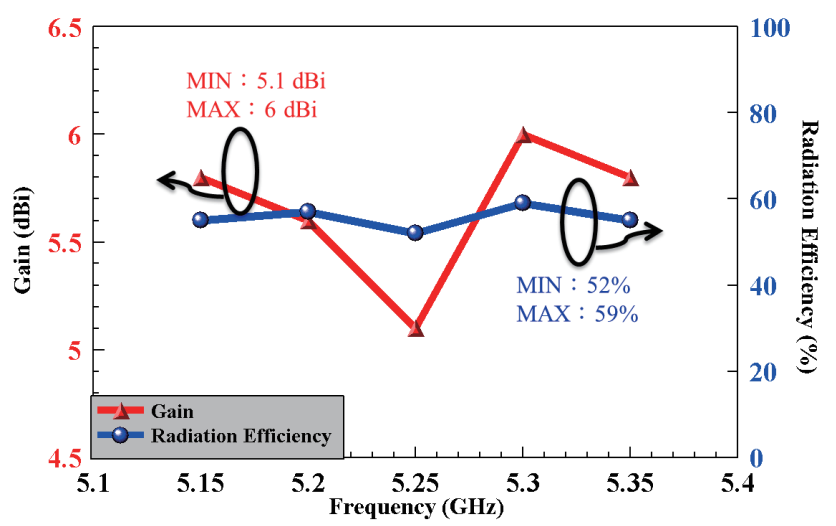

(b)

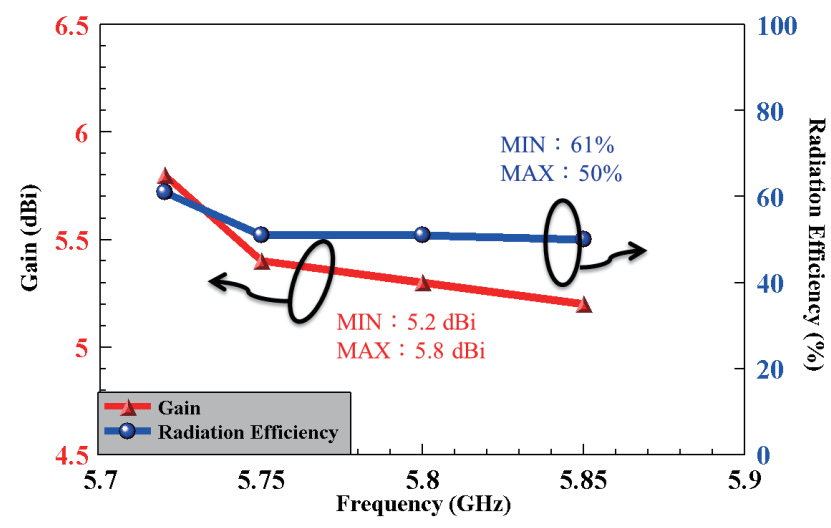

(c)

Fig. 8. (Color online) Measured antenna gains and radiation efficiencies with reflector ( $d=8 \mathrm{~mm}$ ). (a) 2.38-2.5, (b) 5.1-5.4, and (c) 5.7-5.9 GHz.

Table 1

Results of measured antenna gains and efficiencies $(d=8 \mathrm{~mm})$.

\begin{tabular}{lcccc}
\hline Bands $(\mathrm{GHz})$ & Max. gain $(\mathrm{dBi})$ & Min. gain $(\mathrm{dBi})$ & Max. efficiency $(\%)$ & Min. efficiency $(\%)$ \\
\hline $2.4-2.484$ & 4 & 3.5 & 69 & 60 \\
$5.15-5.35$ & 6 & 5.1 & 59 & 52 \\
$5.725-5.825$ & 5.8 & 5.2 & 61 & 50 \\
\hline
\end{tabular}


$\mathrm{dBi}$, and the radiation efficiencies varied from 50 to $61 \%$. As mentioned previously, because the variations of antenna gain and efficiency are only $0.5 \mathrm{dBi}$ and $9 \%$ for $2.4-2.484 \mathrm{GHz}$ bands, $0.9 \mathrm{dBi}$ and $7 \%$ for $5.15-5.35 \mathrm{GHz}$ bands, and $0.6 \mathrm{dBi}$ and $9 \%$ for $5.725-5.825 \mathrm{GHz}$ bands, the proposed antenna reveals good and very stable gains and radiation efficiencies in the $-y$ direction. These are important properties for sensor or energy harvesting applications.

\section{Conclusions}

A design of a triple-band (WLAN 2.4, 5.2, and $5.8 \mathrm{GHz}$ ) slot antenna array with good and stable antenna gains and radiation efficiencies for modern energy harvesting of wireless sensor applications was presented. A metal reflector at a distance of $8 \mathrm{~mm}$ is added above the antenna array to enhance the array's radiation directivity and gains. The simulated and measured return losses are in good agreement, and the measured and simulated $S_{11}$ and $\mathrm{S}_{22}$ values are all lower than $-10 \mathrm{~dB}$. As listed in Table 1, at lower frequencies (2.4-2.484 $\mathrm{GHz}$ bands), the optimum gain and efficiency are $4 \mathrm{dBi}$ and $69 \%$, and its isolation is about $-24 \mathrm{~dB}$. Furthermore, at higher frequencies $(5.15-5.35$ and $5.725-5.825 \mathrm{GHz}$ bands), the array's optimum efficiencies are 59 and $61 \%$, the optimum gains are 6 and $5.8 \mathrm{dBi}$, and the isolation is only $-25 \mathrm{~dB}$. Finally, the proposed antenna array can involve all the WLAN 2.4, 5.2 , and $5.8 \mathrm{GHz}$ bands for sensing even converting electromagnetic energy effectively for the IoT or applications to low power electronic products.

\section{Acknowledgments}

This work was kindly supported by the Ministry of Science and Technology of the Republic of China (MOST 106-2221-E-218-034).

\section{References}

1 Z. M. Gregorio, M. C. Jaime, D. S. Alejandro, and R. P. Jose M: Int. Conf. Computing Systems and Telematics (ICCSAT, 2015) 1510.

2 M. S. Khan and H. Deng: IEEE Int. Symp. Anten. Propag. (APSURSI, 2016) 611.

3 F. Xie, G. M. Yang, and W. Geyi: IEEE Anten. Wirel. Propag. Lett. 12 (2013) 155.

4 A. Mavaddat, S. H. M. Armaki, and A. R. Erfanian: IEEE Anten. Wirel. Propag. Lett. 14 (2014) 515.

5 L. J. Xu, B. Huang, and X. Bai: IEEE Int. Conf. Ubiquitous Wireless Broadband (ICUWB, 2016) 1.

6 U. Olgun, C. C. Chen, and J. L. Volakis: IEEE Anten. Wirel. Propag. Lett. 10 (2011) 262.

7 H. C. Sun, Y. X. Guo, M. He, and Z. Zhong: IEEE Anten. Wirel. Propag. Lett. 12 (2013) 918.

8 H. C. Sun, Y. X. Guo, and Z. Zhong: IEEE Int. Symp. Antennas and Propagation (APSURSI, 2012) 1.

9 J. I. Moon, I. K. Cho, S. M. Kim, and Y. B. Jung: Electro. Lett. 49 (2013) 1050.

10 R. Bahr, J. G. Hester, S. A. Nauroze, A. Georgiadis, and M. M. Tentzeris: IEEE Trans. Microwave Theory Tech. 65 (2017) 1831.

11 X. Li, C. Li, S. M. Kim, Y. B. Jung, F. Xie, G. M. Yang, and W. Geyi: Int. Conf. Computational ProblemSolving (ICCP, 2010) 256.

12 A. M. Shire, N. Abdullah, and E. Mohd: IEEE Student Conf. Research and Development (SCOReD, 2016) 1.

13 M. F. Ismail, M. K. A. Rahim, and M. R. Hamid: 7th European Conf. Antennas Propagation (EuCAP, 2013) 2096.

14 T. Moura, L. Bras, and P. Pinho: IEEE Int. Symp. Antennas and Propagation \& USNC/URSI National Radio Science Meeting (APSURSI, 2015) 2445.

15 M. Arrawatia, M. S. Baghini, and G. Kumar: National Conf. Communications (NCC, 2011) 1. 